\title{
Modification of Coal Samples with Bursting Liability Subjected to Microwave Irradiation
}

\author{
Yingyuan Wen, ${ }^{1,2,3}$ Weiming Guan $\mathbb{D D}^{1,2}$ Hongchao Zhao, ${ }^{1,2}$ Honglin Liu $\mathbb{D}^{1,2}$ Huwei Li, ${ }^{1,2}$ \\ and Qi Qi (i) ${ }^{1,2}$ \\ ${ }^{1}$ School of Geology and Mining Engineering, Xinjiang University, Urumqi 830046, Xinjiang, China \\ ${ }^{2}$ Autonomous Region Experimental Teaching Demonstration Center for Geology and Mining Engineering, Xinjiang University, \\ Urumqi 830047, China \\ ${ }^{3}$ Key Laboratory of Deep Coal Resource Mining, Ministry of Education of China, School of Mines, \\ China University of Mining and Technology, Xuzhou 221116, Jiangsu, China \\ Correspondence should be addressed to Weiming Guan; gwmxju@xju.edu.cn
}

Received 17 April 2021; Revised 31 August 2021; Accepted 9 September 2021; Published 27 September 2021

Academic Editor: Pengfei Wang

Copyright (C) 2021 Yingyuan Wen et al. This is an open access article distributed under the Creative Commons Attribution License, which permits unrestricted use, distribution, and reproduction in any medium, provided the original work is properly cited.

\begin{abstract}
This paper introduces the innovative technique to release the bursting liability of coal seam via microwave irradiation. To verify the feasibility of this environment-friendly technique, a series of laboratory tests incorporating acoustic emission (AE) investigation were carried out. Test results indicated that both the uniaxial compressive strength (UCS) and bursting energy index of raw and water-soaked coal samples were significantly reduced. In particular, the bursting liability was reduced by one level when the values of UCS were compared, the evidence of which is the variation of wave velocities of tested coal samples. It can also be found from the events and hits in the complete stress-strain curve and the cumulative curve of acoustic emission that the elastic modulus of the raw and water-soaked coal samples subjected to microwave irradiation decreased by $58.42 \%$ and $29.63 \%$, respectively. This facilitates the entry into the stage of stable crack propagation more quickly, the growth rate and size of the cracks were slower and more uniform, and there were no smaller coal fragments ejecting during the failure process of the coal samples. Meanwhile, the proportion of high-energy events released in coal samples experienced a decline after the treatment of the microwave. Moreover, microwave heating principally promoted the initiation and expansion of microcracks in coal samples under the influence of microwave power of $1 \mathrm{~kW}$ and a heating time of $120 \mathrm{~s}$, which may cause the overall damage of large fractures to break into multiple small and medium cracks. Based on the experimental results, the conceptual process of using microwave in weakening the bursting liability of coal seam was then proposed, which will be the meaningful reference for microwave-assisted oil recovery and coal bed methane production.
\end{abstract}

\section{Introduction}

Rock bursts have become one of the most severe risks in underground coal mining. As a typical dynamic phenomenon, it generally causes the sudden and severe damage associated with a rapid and violent release of the elastic strain energy attributed to the failure of the rock mass [1-5]. Moreover, some other secondary hazards such as gas outbursts and roof falls will also occur together with the rock bursts, as reported and recorded at home and abroad [6,7]. With the increase of mining depth and intensity of coal mines, rock bursts become more frequent than that of ever before, such as in the USA [8], Australia [9, 10], Poland $[11,12]$, and China [13]. Particularly, more than 177 mines experienced rock burst incidents in China by the end of 2017 [13]. It has been well noted that the occurrence of rock bursts depends not only on mining conditions but also on the burst liability of the coal/rock [14]. Compared with the mining conditions, the burst liability is regarded as an effective warning symbol in the prevention of rock bursts.

In essence, the prevention and control of rock burst are to reduce the burst liability of coal and rock mass around the 
roadway or slope to permit pressure relief and to transfer the high stresses elsewhere at a distance [15]. In terms of coal pressure relief, a large number of studies have been carried out, and lots of practical techniques were then proposed, which include drilling pressure relief [16], water infusion [17], coal blasting [18], and hydraulic cutting [19]. Although these onsite techniques achieved somehow benefits in releasing the pressure, the effectiveness and timeliness of pressure relief are still the main concern for coal operators. Among them, drilling pressure relief and hydraulic cutting are passive in changing the mechanical properties of coal. When the coal seam is hard $(f \geq 3)$, it is not sufficient to fracture the coal mass around the drilling or slit. Coal seam water infusion is believed to be active to weaken the coal mass, but the complex process will take a long time. Different from water infusion, the complicated procedure restricts the wide application of blasting techniques in pressure relief. In addition, the potential misfire and rock bursts attributed to the blasting technique should also be accounted for. On the other hand, both the coal seam water infusion and hydraulic cutting will utilize lots of water and may result in possible water pollution.

Against this background, developing an effective, timely, active, and environment-friendly technique to change the properties of coal mass is becoming urgent for underground coal mines subjected to rock bursts. The authors of this paper presented an innovative technique in treating the coal mass via microwave irradiation. Herein, microwave refers to the electromagnetic wave with a frequency of $300 \mathrm{MHz}-3000 \mathrm{GHz}(3 \mathrm{THz})$, and the frequency used by industrial, scientific, and medical (ISM) departments is $915 \mathrm{MHz}$ and $245 \mathrm{GHz}$ [20]. These frequencies were chosen by international agreement to minimize the interference with communication services.

Microwave heating is a result of interaction between dipoles in materials and electromagnetic fields. The dipoles are irregularly aligned without an electromagnetic field (Figure 1(a)). As shown in Figures 1(b) and 1(c), when applying the microwave irradiation to materials, the dipoles in a microwave field attempt to reorient themselves with the rapidly changing field $\left(2.4 \times 10^{9}\right.$ per second at a frequency of $2.45 \mathrm{GHz})$ [21]; this movement give rise to friction and therefore cause them to warm up [22].

In general, microwaves are either transmitted, reflected, or absorbed by a material depending on its dielectric properties (Figure 2) [23]. Dielectric constant $\left(\varepsilon^{\prime}\right)$ and dielectric loss factor $\left(\varepsilon^{\prime \prime}\right)$ were usually used to characterize the dielectric properties of a material, and the two parameters can be subsumed in the complex permittivity $\left(\varepsilon^{*}\right)$ in the following form [24]:

$$
\varepsilon^{*}=\varepsilon^{\prime}-i \varepsilon^{\prime \prime} .
$$

Dielectric constant $\left(\varepsilon^{\prime}\right)$ reflects the capacity of the material to store electromagnetic energy, and dielectric loss factor $\left(\varepsilon^{\prime \prime}\right)$ represents the dissipation of the stored energy into heat.

When irradiating a material with heterogeneous dielectric properties, microwaves can selectively heat the adsorbing phase while passing through the transparent phase. It was verified that the organic components of coal appear transparent to microwaves and have low dielectric permittivity, whereas the dipoles (i.e., moisture and some minerals including pyrite) have higher permittivity (e.g., $\varepsilon^{\prime \prime}$ of water reaches 78.54 at $25^{\circ} \mathrm{C}$ ) [25], which leads to thermal stress difference between materials with different permittivity.

In recent years, microwave heating has gained widespread popularity in coal drying, desulphurization, pyrolysis, grinding, and coal bed methane [20, 26-29]. Among these, the research results in the field of grinding and coal bed methane showed that microwave treatment can lead to the formation of new cracks and promote the expansion of the original cracks in coal mass [30]. Furthermore, Marland et al. [31] and Lester et al. [32] showed that the overall effect of microwave radiation on the coal calorific value and chemical characteristics were minimal, especially under the condition of high power and short time, so the effect on the industrial application of coal was considered to be negligible.

At present, most research primarily focused on the formation mechanism and evolution characteristics of fissures and the formation and development of fissures that will inevitably change the mechanical properties of coal mass. However, little attention has been devoted to the mechanical properties and the physical phenomena (acoustic emission, wave velocity, and electromagnetic radiation) of coal mass heated by microwave. These results were very important for the application of microwave irradiation in the mechanical modification of coal with burst liability.

The major objective of this study is to assess the feasibility of the innovative technique to weaken the bursting liability of coal mass via microwave irradiation. In this paper, raw and water-soaked coal samples were selected for microwave heating, and a suite of integrated diagnostic techniques, including mechanical testing system (MTS) and acoustic emission (AE), were employed to monitor the variation characteristics of mechanical properties and physical phenomena. Additionally, failure characteristics of coal samples before and after microwave treatment were observed and analyzed. After that, an engineering application method for microwave weakening the bursting liability of coal was proposed.

\section{Experimental Materials and Methods}

2.1. Preparation of Coal Samples. All coal samples used in this research were sourced from a coal mine in Shandong, China. A total of twelve cube specimens with dimensions of $50 \mathrm{~mm} \times 50 \mathrm{~mm} \times 100 \mathrm{~mm}$ were prepared and tested. The test results of the bursts liability of coal seam are listed in Table 1.

2.2. Experimental Procedure. The experimental procedure is illustrated in Figure 3, in which the solid black and dotted arrows designate the experimental sequence, while the red arrows indicate the experimental monitoring process. The 


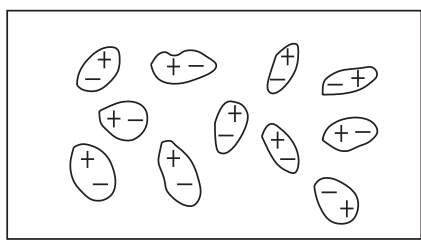

(a)

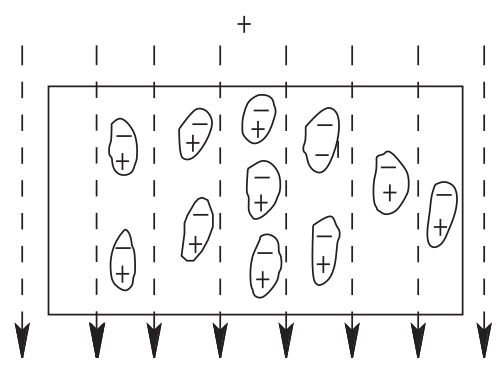

(b)

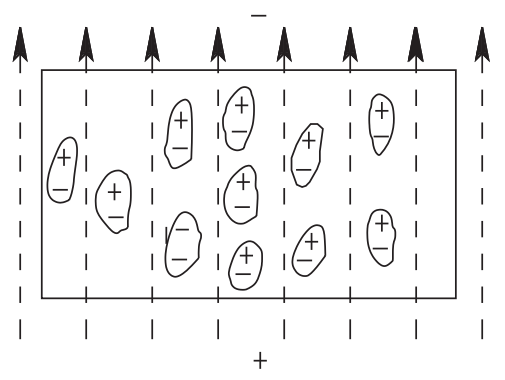

(c)

Figure 1: Realignment of dipoles in an electromagnetic field.

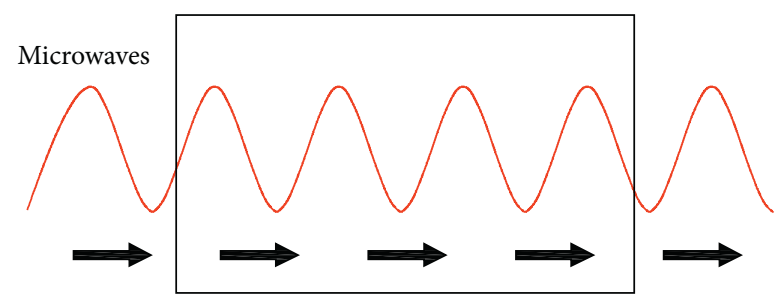

(a)

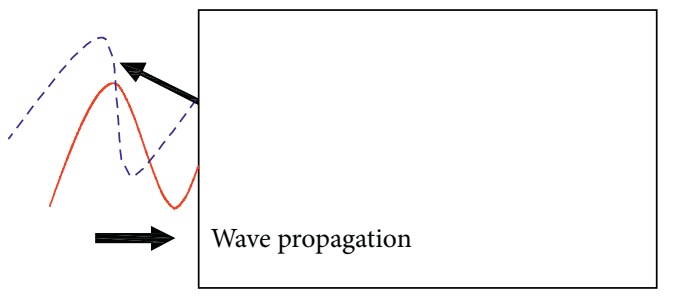

(b)

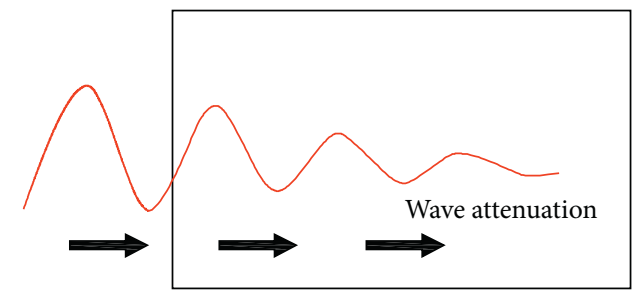

(c)

FIgURE 2: The behavior of a material within a microwave field [23].

TABLE 1: The bursts liability results of No.3 coal seam.

\begin{tabular}{lccccc}
\hline \multirow{2}{*}{ Coal seam } & \multicolumn{2}{c}{ Identification index of bursts liability } & $R_{\mathrm{c}}$ & Identification result \\
& $D_{T}$ & $W_{\mathrm{ET}}$ & $K_{\mathrm{E}}$ & 9.36 & II weak bursting liability \\
\hline No.3 & 1824 & 2.90 & 5.60 &
\end{tabular}

Notes: DT is the duration of dynamic fracture; WET is elastic strain energy index; KE is bursting energy index; RC is uniaxial compressive strength (UCS).

black dotted line represents the raw coal samples, which refer to the coal sample without any treatment, marked CGN and CGY before and after the microwave heating. The solid line represents water-soaked coal samples coal sample, referring to the coal sample immersed in water for $24 \mathrm{~h}$ in the vacuum cylinder, named HSN and HSY before and after microwave heating, respectively. Each of the above four groups contained three coal samples (namely, CGN1-1, CGN1-2, and CGN1-3). In a single experiment, the moisture content of coal samples was measured, and the loading process was synchronous with AE monitoring and the highspeed camcorder.

2.3. Microwave Heating System. Microwave heating was carried out in special microwave equipment which was provided by the He Nan Xin Hang Microwave Technology Co., Ltd., China, with adjustable powers at $2.45 \mathrm{GHz}$ (see Figure $3(\mathrm{~b})$ ). The microwave equipment consisted of two microwave generators, two rectangular waveguides, a resonant cavity, and a control system. The microwave power is either $1 \mathrm{~kW}$ or $2 \mathrm{~kW}$, which are selectable. In this research, all coal samples were heated for 120 s in the microwave equipment with a power of $1 \mathrm{~kW}$.

2.4. Loading and Monitoring System. All coal samples were tested on the electrohydraulic servo material test system (MTS-C64.106). The constant displacement rate of $3 \times 10^{-2} \mathrm{~mm} / \mathrm{s}$ was adopted in this research for all tested specimens (see Figure 3(d)). The PCI-2 AE System from Physical Acoustics Corporation (PAC) was applied in this 


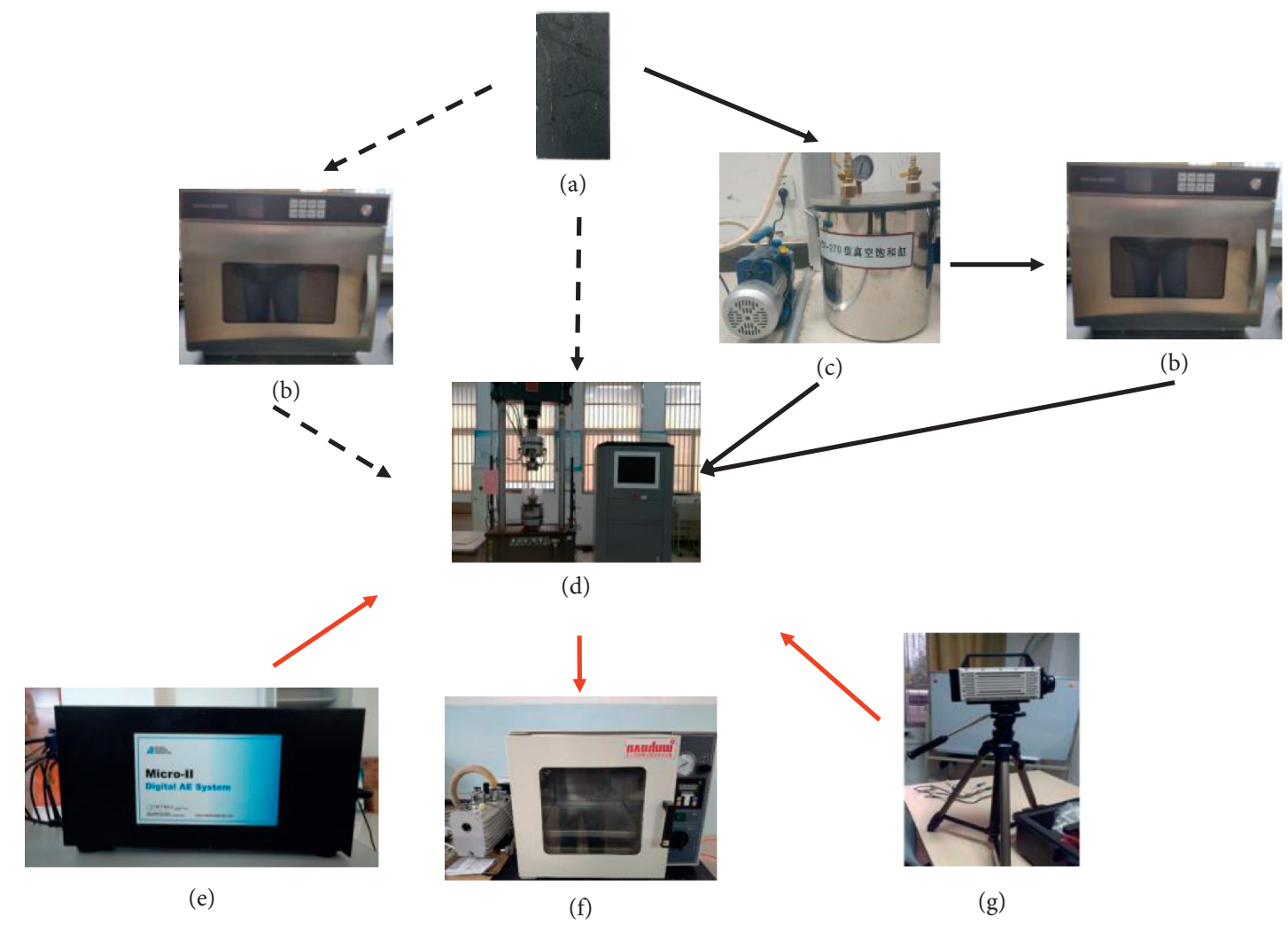

FIGURE 3: Experimental procedure and the corresponding apparatuses.

research. The main feature of this monitoring equipment is that it can acquire AE transient waveform in real-time, with waveform processing and real-time $\mathrm{AE}$ events location. As shown in Figure 4, 8 sensors (R15a) were symmetrically fixed around the coal sample for AE signal acquisition, with an operating frequency of $100-400 \mathrm{kHz}$. Each sensor was equipped with a 2/4/6c type preamplifier. NAC Digital HighSpeed Camcorder (GX-3) was used to record the loading process of coal samples, which had ultrahigh photosensitivity, $21.7 \mu \mathrm{m}$ pixel, and a high dynamic range. Moreover, the frame rate could reach 198000 frames/s. In these experiments, the frame rate was set at 4000 frames per second (fps) and the resolution was $1024 \times 768$. Test set-up and instrument can be found in Figure 5 .

2.5. Configuration Setting for AE Data Acquisition. The noise detection threshold was set at $35 \mathrm{~dB}$ with the consideration of the prevailing background noise. To ensure accurate data acquisition, the peak definition time (PDT), the hit definition time (HDT), and the hit lock-out time (HLT) were set to 50,200 , and $300 \mu \mathrm{s}$, respectively [5]. The preamplifier amplification was concurrently set at $40 \mathrm{~dB}$, while the sampling frequency was $2 \mathrm{MHz}$. The velocity of acoustic wave transmission through the coal sample was determined via the acoustic characteristic matrix test. In addition, the acoustic emission events were monitored with the difference in arrival time of the sound waves. In this research, the vaseline was used to couple the $\mathrm{AE}$ sensors effectively onto the coal samples.

\section{Results and Analysis}

\subsection{The Variation Characteristics of Bursting Liability and Wave Velocity of Coal Samples before and after Microwave Heating}

3.1.1. Indices of Bursting Liability. The sensitivity of the coal samples subjected to microwave heating and the declined strength of coal samples made it difficult to accurately control to a $75 \%$ to $85 \%$ level of the ultimate load during cyclic loading. Consequently, the calculation of elastic strain energy $\left(W_{E T}\right)$ was prone to large errors. Depending on the different failure modes, artificially subjective factors influence the calculation of the duration of dynamic fracture $\left(D_{T}\right)$. Therefore, the bursting energy $\left(K_{E}\right)$ and uniaxial compressive strength $(R c)$, being more reliable, were selected for comparative analysis. Figure 6 illustrates the complete stress-strain curves of typical coal samples under uniaxial compression. The stress-strain variation patterns were consistent with low peak dispersion, leading to high reliability and minimal error for data analysis. Table 2 lists the bursting liability index, wave velocity, and moisture content of tested coal samples before and after microwave heating. For a clearer comparative analysis, the mean and the standard deviation for each group of data are plotted in Figure 7 for reference.

As can be seen from Table 2, the maximum, minimum, and average values of the UCS of the raw coal samples before microwave (CGN) were $11.54 \mathrm{MPa}, 10.93 \mathrm{MPa}$, and 11.35 MPa, respectively. It was slightly higher than that of 


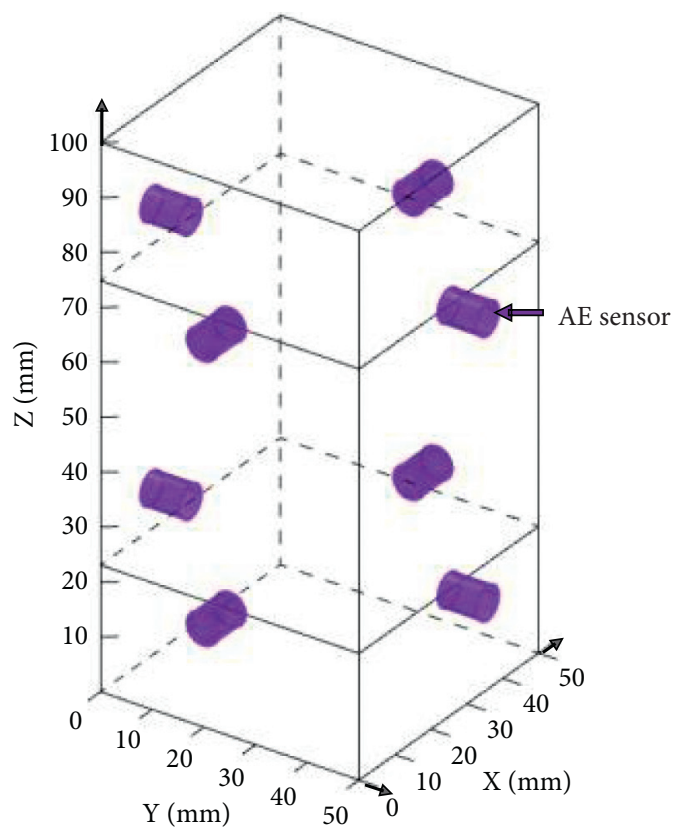

(a)

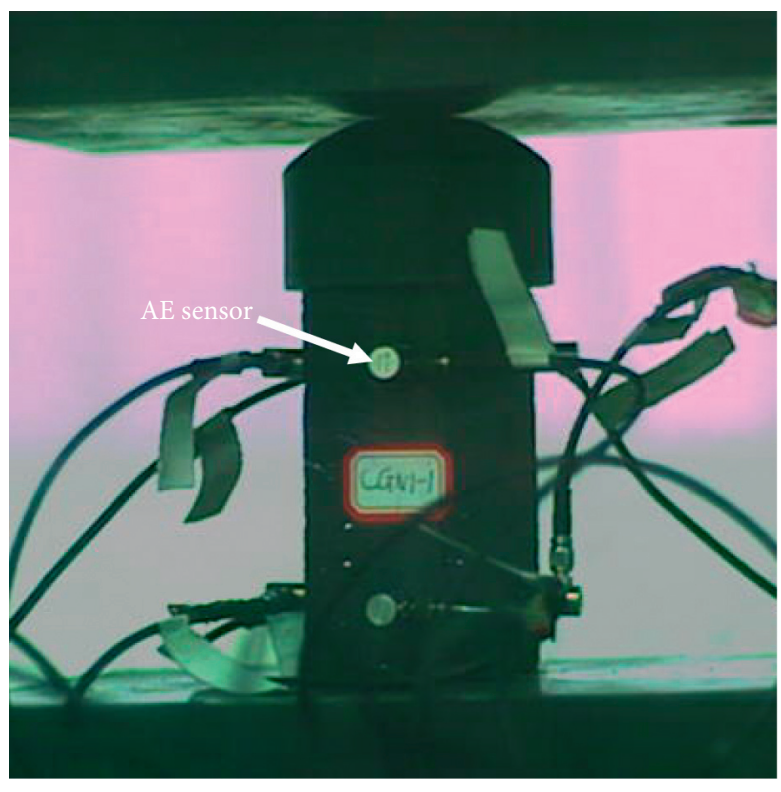

(b)

Figure 4: Layout of AE sensors. (a) Schematic layout of AE sensors. (b) Real layout of AE sensors.

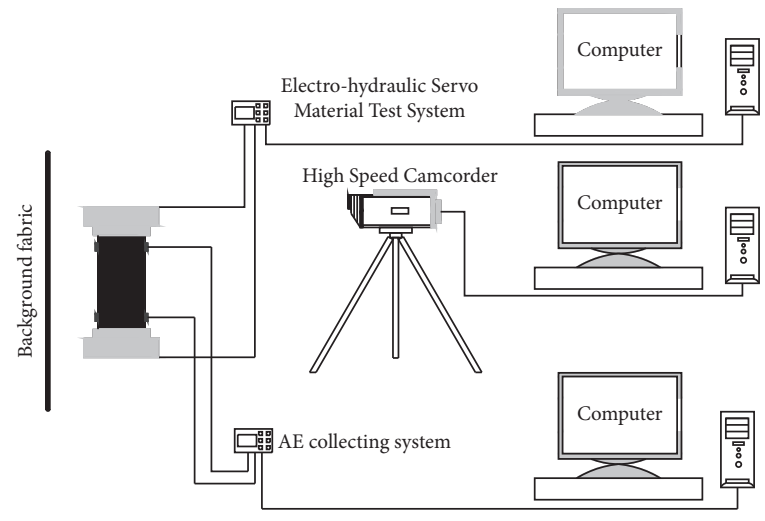

(a)

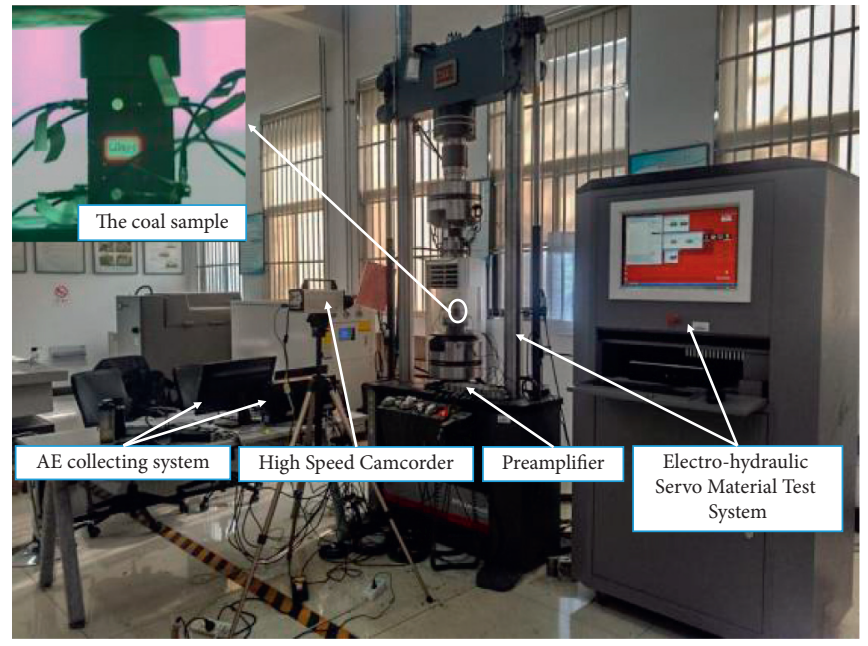

(b)

FIGURE 5: Layout of loading and monitoring. (a) Schematic layout of loading and monitoring. (b) Real layout of loading and monitoring.

specified values presented in the bursting liability identification. The maximum, minimum, and average values of bursting energy $\left(K_{E}\right)$ were $6.54,4.02$, and 5.02 , respectively. The average value was almost the same as that specified in identifying the result of bursting liability. Both belong to the "strong bursting liability" class.

The UCS and bursting energy decreased by $73.74 \%$ and $64.54 \%$, respectively, with the average values being $2.98 \mathrm{MPa}$ and 1.78 times for the raw coal samples exposed to microwave heating (CGY). The corresponding class for bursting liability was reduced from "weak " and "strong" to "none" and "weak" (Figure 7). As a result, the bursting liability of the CGY was significantly reduced, even to the level of "no bursting liability."

The average values of UCS and bursting energy of the water-soaked coal samples before microwave heating (HSN) were $9.10 \mathrm{MPa}$ and 4.10 , respectively. Compared with the CGN, the values decreased by $19.82 \%$ and $18.33 \%$. It suggests that the water intrusion had a significant weakening effect on the mechanical properties of the coal, which agrees well with such findings by other investigators [7]. However, it is notable that the reduction was limited in this investigation. When the water-soaked coal samples were irradiated by microwaves (HSY), the UCS and bursting energy index 

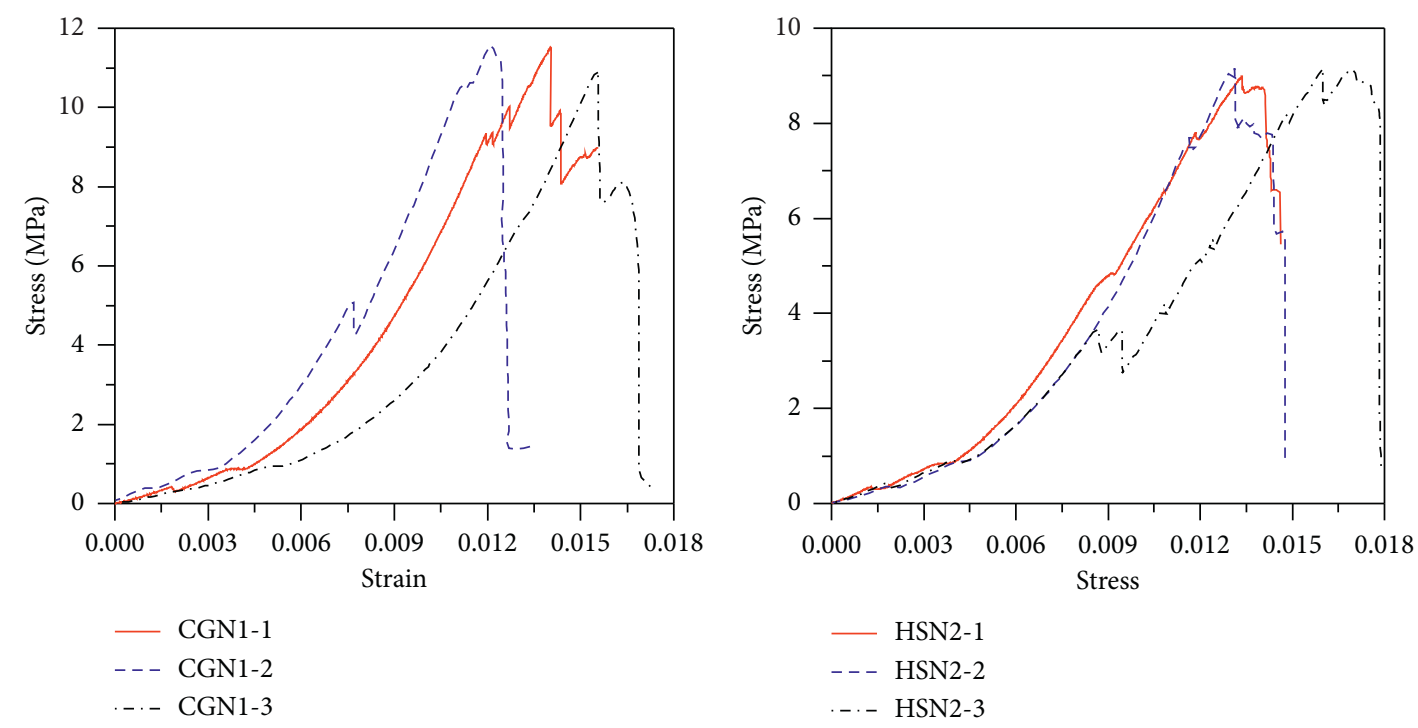

(a)
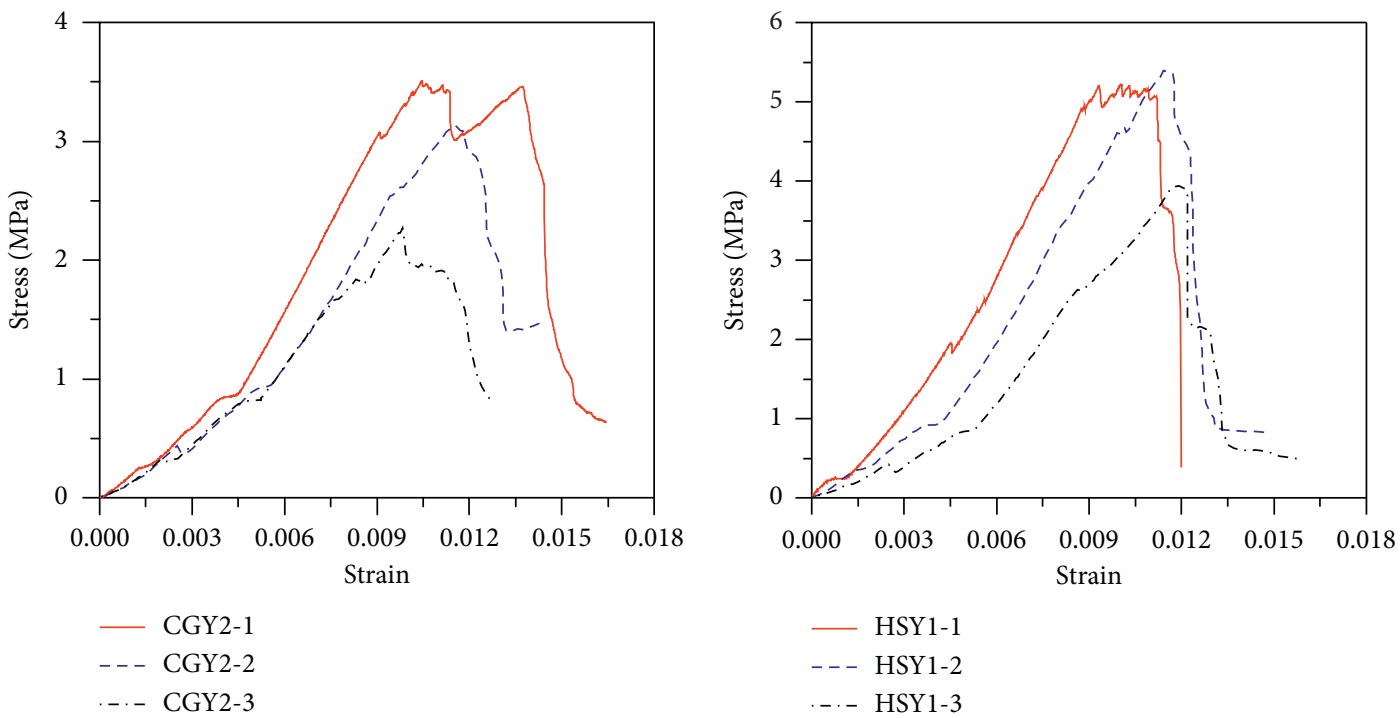

(c)

(d)

FiguRE 6: The stress-strain curves for coal samples before and after microwave heating: (a), (b) raw and water-soaked coal samples before microwave heating, and (c, d) raw and water-soaked coal samples after microwave heating.

TABLE 2: Related parameters for the 12 samples used in the uniaxial compression-acoustic emission tests.

\begin{tabular}{lcccc}
\hline Serial number & P-wave velocity $(\mathrm{m} / \mathrm{s})$ & UCS $(\mathrm{MPa})$ & Bursting energy & Moisture content $(\%)$ \\
\hline CGN 1-1 & 1142.95 & 11.54 & 4.02 & 1.80 \\
CGN 1-2 & 1155.94 & 11.59 & 6.54 & 1.87 \\
CGN 1-3 & 1116.49 & 10.93 & 1.51 & 1.75 \\
CGY 2-1 & 636.90 & 3.51 & 2.40 & 1.48 \\
CGY 2-2 & 409.35 & 3.15 & 1.91 & 1.30 \\
CGY 2-3 & 461.19 & 2.27 & 5.53 & 1.65 \\
HSN 2-1 & 948.01 & 9.00 & 3.17 & 2.68 \\
HSN 2-2 & 922.37 & 9.16 & 3.15 & 2.81 \\
HSN 2-3 & 1130.81 & 9.15 & 1.67 & 2.99 \\
HSY 1-1 & 498.24 & 5.22 & 3.10 & 2.23 \\
HSY 1-2 & 706.82 & 5.38 & 3.68 & 2.21 \\
HSY 1-3 & 508.97 & 3.94 & & 2.36 \\
\hline
\end{tabular}




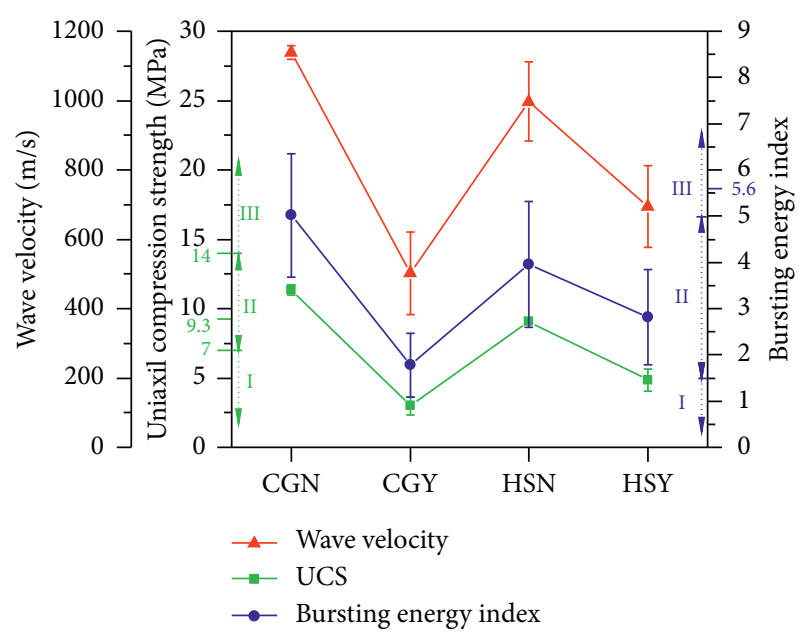

FIGURE 7: Variations in bursting liability indices and wave velocity of coal samples before and after microwave heating: I, II, and III classification of bursting liability (I-none, II-weak, and III-strong).

were decreased by $46.70 \%$ and $32.22 \%$, respectively. The UCS value was reduced from "weak bursting liability" to "no bursting liability," whereas the bursting energy value still indicated "weak bursting liability" although it was greatly reduced.

Concerning the small dispersions in UCS, the bursting liability of either raw or water-soaked coal samples exhibited a significant drop from "weak bursting liability" to "no bursting liability" with microwave radiation. The bursting energy had a higher dispersion than the UCS, especially in the coal samples before microwave heating. The main reason for this was that the coal samples showed the expected brittle characteristics, and there were still multiple peaks and energy accumulation processes (stress-rising phases) in the postpeak stage. From the perspective of energy accumulation and dissipation, the actual value of bursting energy was different from the theoretical value, which resulted in a higher dispersion.

3.1.2. Wave Velocity. The different wave velocity indicates the external expression of the heterogeneity in coal and rock mass. The denser the material, the higher the elastic wave transmission efficiency and the larger the wave velocity. On the contrary, if the medium is loose and homogeneous, elastic waves will appear refracted, scattered, and weakened when passing through interfaces of different media. Thus, the consequent energy dissipation in the process decreases the wave velocity.

After microwave heating, the wave velocity in coal samples was reduced, and the average velocity of raw and water-soaked coal samples decreased by $55.86 \%$ and $33.83 \%$, respectively. This showed that the cracks in coal samples were more developed. Furthermore, the average wave velocity of raw coal samples decreased slightly by $7.85 \%$ after being immersed in water. This result concurs with previously published results [33]. Therefore, in place of the destructive test, the wave velocity can be used as a monitoring parameter to test the weakening effect in-situ.

\subsection{Relationship between Axial Stress and Axial Strain.} Although the bursting liability indices are capable of reflecting the mechanical characteristics of coal samples, they were all based on the stress-strain curves. The influence of microwave irradiation on coal samples should be further investigated to obtain a better understating of this observation. Accordingly, 5 distinctive stages of the crack development process (crack closure, elastic deformation, stable crack propagation, unstable crack propagation, and postpeak failure) can be identified in these curves [34]. For comparison, the stress-strain curve of the typical coal sample from each group is selected and plotted in Figure 8. This showed that the elastic modulus of the coal samples decreased after microwave heating. In this study, we used the average modulus as the elastic modulus [35]; assuming that the strain-stress formula has the form $\sigma=f(\varepsilon)$, the elastic modulus can be derived from the following equation:

$$
E=\frac{f\left(\varepsilon_{1}\right)-f\left(\varepsilon_{2}\right)}{\varepsilon_{1}-\varepsilon_{2}},
$$

where $E$ is the elastic modulus, $\varepsilon_{1}$ and $\varepsilon_{1}$ represent the strain of the starting and ending position across the elastic stage, respectively, and $f\left(\varepsilon_{1}\right)$ and $f\left(\varepsilon_{2}\right)$ represent the stresses at the same start and end positions, respectively.

At the initial loading stage, the stress-strain characteristics of all coal samples before microwave heating (CGN and HSN) were concave. The subsequent linear segment depicting the elastic stage was smooth and long, with a steep slope, conforming to the phenomenon of crack closure that occurs in the elastic stage. The average elastic modulus of raw and water-soaked coal samples was $1.01 \mathrm{GPa}$ and $0.81 \mathrm{GPa}$, respectively. Figure 8 shows that at the peaks of the stressstrain curves for the coal samples before microwave heating (CGN1-1 and HSN2-3). It is apparent that the stress and strain at the peak were larger and a large amount of elastic energy was accumulated before the peak. The stress-strain curve after the peak fell abruptly and became approximately linearly. Additionally, the large stress drops occurred after the peak and over a small strain increase, indicating that the cracks rapidly expanded and released the energy accumulated before the peak, with the and coal samples exhibiting brittle behavior. Furthermore, such stress drops may cause mine earthquakes, resulting in cumulative damage to the roadway in the vicinity of the rock.

The initial portion of the stress-strain characteristics of coal samples after microwave heating (CGY and HSY) exhibited a shorter concave stage, and the linear segment in the elastic stage was not smooth and long with a gentler slope. Meanwhile, the boundary between crack closure and elastic deformation stage was not easily discernible. These changes were attributed to more microcracks being caused by microwave heating and the cracks expanding while some closed under axial loading. According to equation (1), the average elastic modulus of raw and water-soaked samples are $0.42 \mathrm{GPa}$ and $0.57 \mathrm{GPa}$, respectively. These showed a 


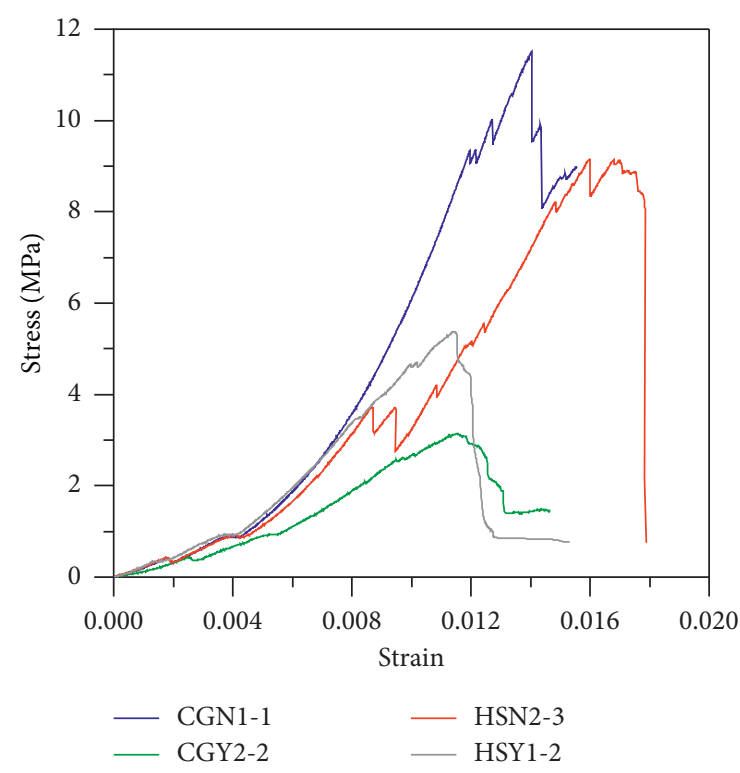

FIGURE 8: Comparison of stress-strain curves of the coal samples before and after microwave heating.

decrease of $58.42 \%$ and $29.63 \%$ compared with that before microwave heating. The accumulated energy before the peak decreased with the reduction of peak stress and strain, and the postpeak curves gradually dropped to the residual strength. Moreover, the curves showed a lesser stress decrease over a larger strain range, causing the slope of stress drop to be gentler. Consequently, the potential occurrence of rock bursts was reduced when the coal mass was exposed to microwave irradiation.

\subsection{Acoustic Emission Characteristics}

3.3.1. The Characteristic Variations in Acoustic Emission Parameters. Acoustic emission (AE) was recognized as one of the most direct methods to study the mega-damage evolution of rock failure under loading. In this research, we focused on the characteristics of energy release of coal samples before and after microwave heating under loading. As a result, the events, hits as well as energies were counted by the event count and hit count (see Table 3).

According to the records of event count, the signals of high-energy events can be received by 4 or more AE sensors. This procedure was similar to the event monitoring with the microseismic monitoring system on-coal samples were exposed to microwave irradiation, microcracks increased, and the vibration signals caused by partial microcracks expansion were weak. They were not strong enough to be received by the $4 \mathrm{AE}$ sensors, and thus the hit count was used for statistics, similar to signals monitored by the AE monitoring system onsite.

Coal mining is easily susceptible to the high-energy events caused by dynamic loads. It was, therefore, practically significant to reduce the frequency of the large energy events to prevent the occurrence of onsite rock bursts. To analyze the variation of high-energy events before and after microwave heating, additional statistical records were made of the high-energy event counts and the " $b$ value" determined from the hit count data.

Figure 9 shows the percentage of event frequency and energy over each interval. Although the percentage of events is relatively low in the two intervals (1e4-1e5] and (1e6-+o), the proportion of energy released was high, even more than $70 \%$. Figure 9 (a) enables the comparison of the frequency records between CGN and CGY. The frequency percentage of large energy events $(1 \mathrm{E} 5-+\infty)$ of the CGY was far less than that of the CGN. Similarly, the energy percentage of large energy events $(1 \mathrm{E} 6-+\infty)$ of the CGY was similarly lower. Moreover, an interesting phenomenon is drawn from Figure 9(a) that the frequency percentage of low-energy events (0-1E2] of the CGY was lower. This phenomenon is believed to be attributed to the expansion of microcracks when the samples were heated by microwave irradiation. It was similar to the original low-energy events under uniaxial loading.

The interpretation and physical meaning of " $b$ values" has been extensively studied by seismologists [36]. The $b$ value reflects the proportion of large-magnitude earthquakes relative to small-magnitude earthquakes. Consequently, a greater number of larger-magnitude events yield a smaller $b$ value [37]. In rock mechanic testing, the generation or expansion of microcracks will release elastic waves that are similar to earthquakes. In $\mathrm{AE}$ applications, the peak amplitude was substituted for $M$ in the Gutenburg-Richter law, an equation widely used in the fields of concrete fracture and rock mechanics as follows:

$$
\lg N=a-b \frac{A_{\mathrm{dB}}}{20} .
$$

Figure 10 presents the relationship between the frequency and amplitude of the AE hits (i.e., higher than the threshold of $35 \mathrm{~dB}$ ). Regardless of the coal samples being exposed to microwave irradiation or not, the number of $\mathrm{AE}$ hits with amplitudes between 35 and $40 \mathrm{~dB}$ was the greatest and subsequently decreased with increasing amplitude. It was also noteworthy that the number of AE hits of the CGY was more than that of the CGN for the same intervals. Figure 11 illustrates the correlated results for $\mathrm{AE}$ hits of the CGN and CGY per equation (2), and the values of $b$ for three coal samples in each of the CGN and CGY series were $1.1349,1.1630,1.1241$ and $1.2548,1.1819,1.2475$ with average values of 1.1407 and 1.2281 , respectively. It is also evident that the $b$ value of each coal sample exposed to microwave irradiation increased, while the proportion of the number of high-energy hits decreased.

3.3.2. Relationship between the Stress-Strain Curve, the Cumulative AE Hits, and Events. Figure 12 presents the holistic record of $\mathrm{AE}$ events and hits that occurred throughout the loading process of the coal samples. Based on the analysis for various features of the cumulative curves of AE events and hits of the CGN and CGY (taking CGN1-1 and CGY2-2 as examples), the curves consist of three distinct stages: oa, ab, and bc. "Oa" represented the initial stage 
TABLE 3: AE parameters of coal samples before and after microwave heating under uniaxial loading.

\begin{tabular}{lcccccc}
\hline \multirow{2}{*}{ Serial number } & \multicolumn{3}{c}{ The statistics of event count } & \multicolumn{2}{c}{ The statistics of hit count } \\
& Events & Energy (aJ) & Average energy(aJ) & Hits & Energy(aJ) & Average energy(aJ) \\
\hline CGN1-1 & 366 & $2.33 \mathrm{E}+07$ & $6.37 \mathrm{E}+04$ & 14791 & $2.80 \mathrm{E}+07$ & $1.89 \mathrm{E}+03$ \\
CGN1-2 & 457 & $3.52 \mathrm{E}+07$ & $7.70 \mathrm{E}+04$ & 27300 & $8.85 \mathrm{E}+07$ & $3.24 \mathrm{E}+03$ \\
CGN1-3 & 610 & $3.75 \mathrm{E}+07$ & $6.15 \mathrm{E}+04$ & 28120 & $8.59 \mathrm{E}+07$ & $3.05 \mathrm{E}+03$ \\
CGY2-1 & 453 & $1.56 \mathrm{E}+07$ & $3.44 \mathrm{E}+04$ & 83144 & $3.01 \mathrm{E}+08$ & $3.62 \mathrm{E}+03$ \\
CGY2-2 & 399 & $1.13 \mathrm{E}+07$ & $2.83 \mathrm{E}+04$ & 69280 & $1.56 \mathrm{E}+08$ & $2.25 \mathrm{E}+03$ \\
CGY2-3 & 617 & $0.92 \mathrm{E}+07$ & $1.49 \mathrm{E}+04$ & 42214 & $1.49 \mathrm{E}+08$ & $3.53 \mathrm{E}+03$ \\
HSN2-1 & 315 & $0.50 \mathrm{E}+07$ & $1.59 \mathrm{E}+04$ & 34488 & $1.09 \mathrm{E}+08$ & $3.16 \mathrm{E}+03$ \\
HSN2-2 & 700 & $0.59 \mathrm{E}+07$ & $8.43 \mathrm{E}+03$ & 34111 & $0.75 \mathrm{E}+08$ & $2.20 \mathrm{E}+03$ \\
HSN2-3 & 281 & $7.24 \mathrm{E}+07$ & $2.58 \mathrm{E}+05$ & 33387 & $5.21 \mathrm{E}+08$ & $1.56 \mathrm{E}+04$ \\
HSY1-1 & 717 & $2.27 \mathrm{E}+07$ & $3.17 \mathrm{E}+04$ & 36560 & $8.15 \mathrm{E}+08$ & $2.23 \mathrm{E}+04$ \\
HSY1-2 & 506 & $0.84 \mathrm{E}+07$ & $1.66 \mathrm{E}+04$ & 44725 & $2.34 \mathrm{E}+08$ & $5.23 \mathrm{E}+03$ \\
HSY1-3 & 808 & $1.45 \mathrm{E}+07$ & $1.79 \mathrm{E}+04$ & 48717 & $1.55 \mathrm{E}+08$ & $3.18 \mathrm{E}+03$ \\
\hline
\end{tabular}

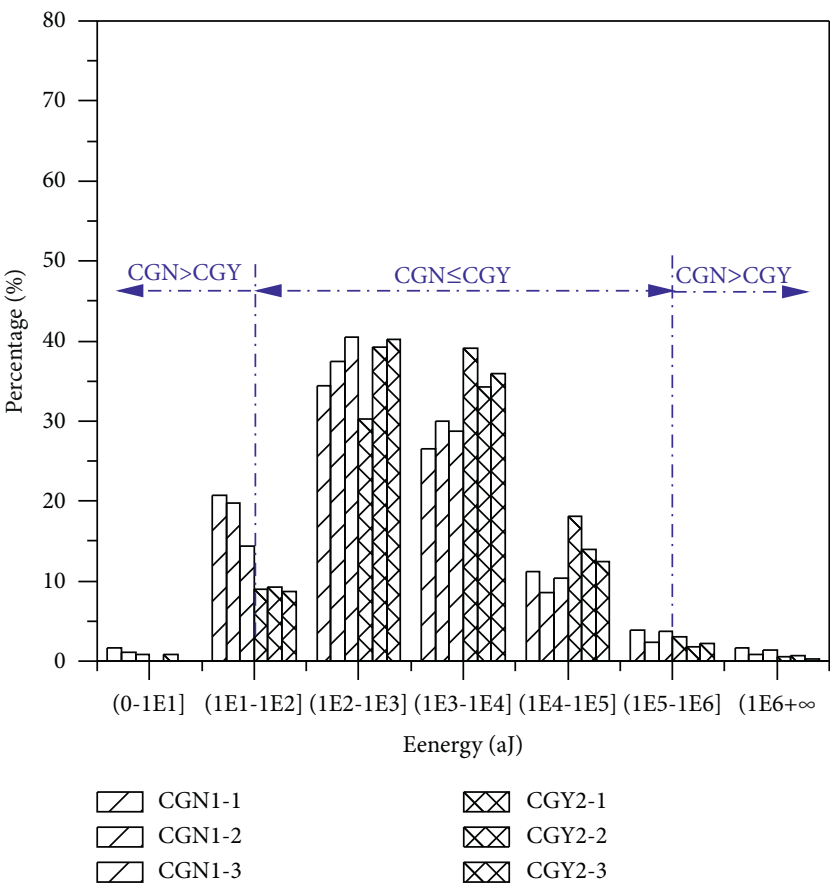

(a)

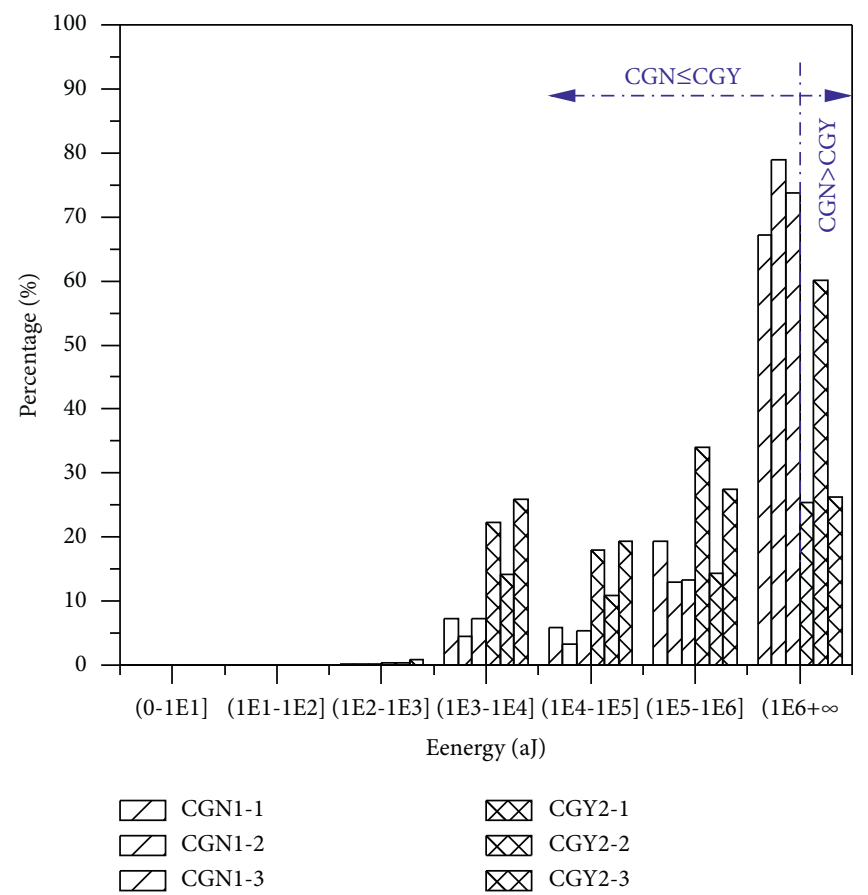

(b)

FIGURE 9: Event frequency and energy percentage of events with different levels of the CGN and CGY: (a) frequency, (b) energy.

with a lower rising rate, "ab" represented the stage with a higher rising rate, and "bc" represented the final multistepped rising stage.

Regardless of the coal samples being exposed to microwave irradiation or not, the cumulative curves of $\mathrm{AE}$ events and hits of coal samples fall into three stages, as discussed above. Herein, the "oa" stage of the CGN is defined as the crack closure phase of the stress-strain curve, the "ab" stage represented the elastic deformation phase, and the "ob" stage accounted for a high proportion of the whole curve. The "bc" stage showed a move from the elastic deformation phase to metastable crack propagation phases, that is to say, passing point $b$, the $\mathrm{AE}$ events and hits began to increase stepwise, and the size of the step gradually increased.
However, the points "a" and "b" on the cumulative curves of AE events and hits of the CGY were left shift, as shown in Figure 12. Namely, the proportion of "ab" phase decreased, and the proportion of "bc" phase was more dominant. These changes indicated that the coal samples had entered a stable crack propagation phase more quickly under uniaxial loading due to the microcracks or expansion caused by microwave heating. Consequently, the elastic deformation stage was shortened. It should be noted that the actual position of point $c$ in Figure 12(a) should be closer to the peak stress (i.e., the actual proportion of "bc" stage should be higher) because the CGN1-1 suddenly ruptured and vibrated when the stress approached the peak stress. Its sound was so audible during this failure process that some AE sensors 


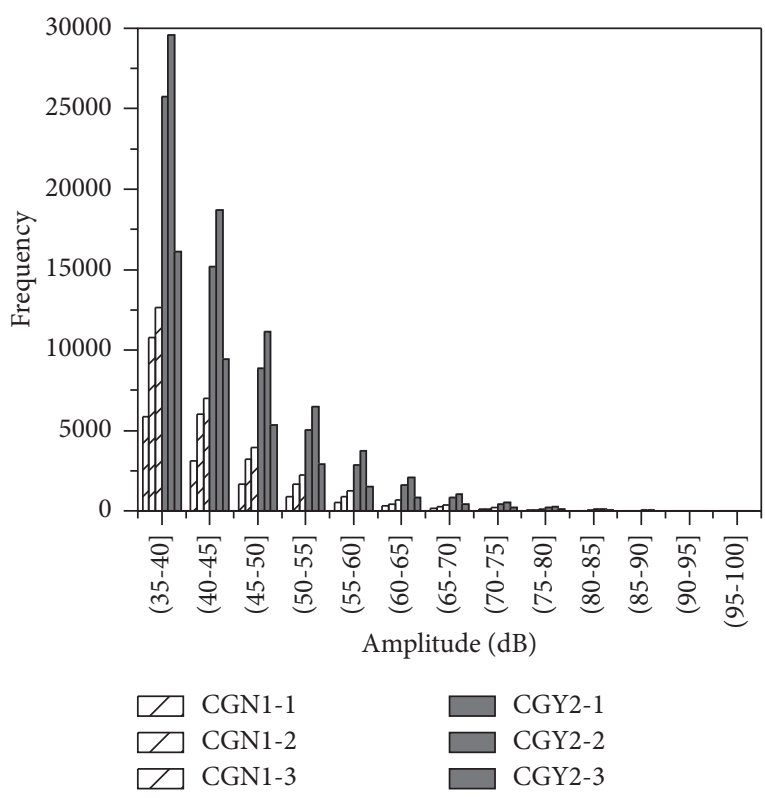

(a)

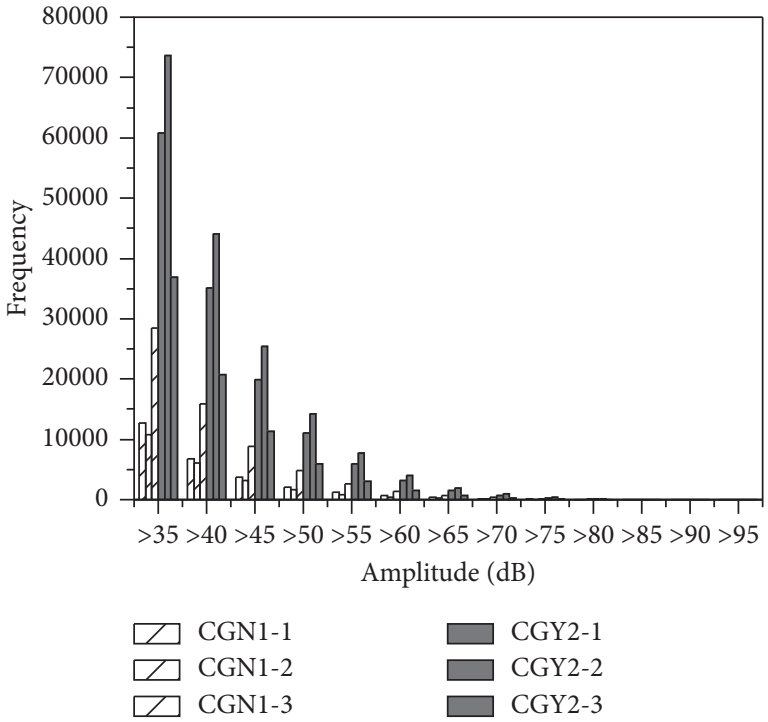

(b)

FIGURE 10: Statistical relationship between AE amplitude and frequency for the CGN and CGY: (a) the amplitude distribution, (b) the cumulative amplitude distribution.

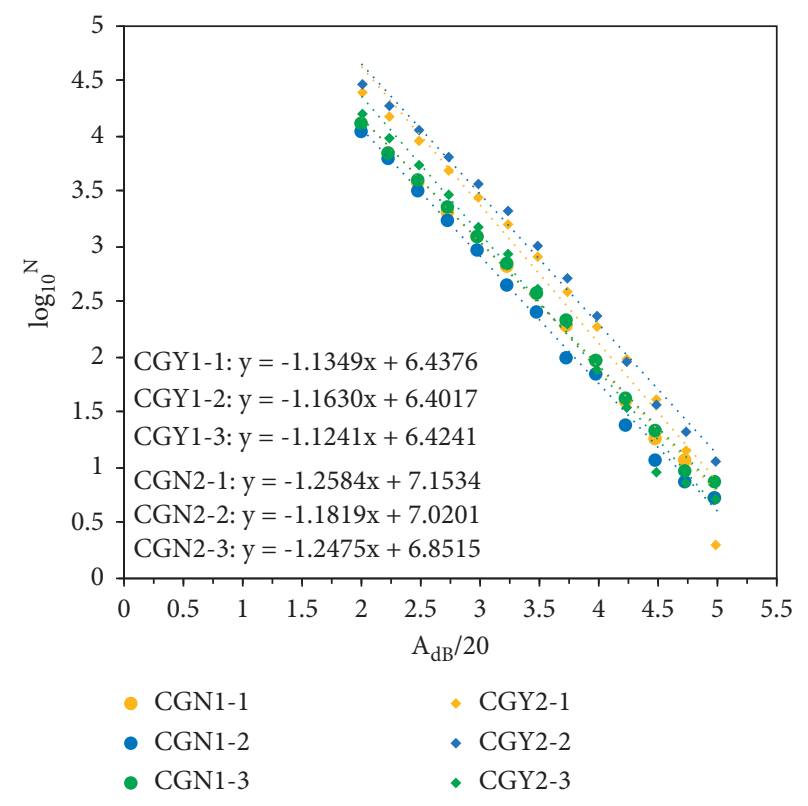

FIGURE 11: The correlated results for the AE amplitude-frequency records for the CGN and CGY.

fixed around the CGN1-1 were loosened or even dropped due to vibrations, and the subsequent vibration signals were not received. However, these should be events and hits near the peak stress, judging from the sound and stress drops.

There were also differences in the step size changes of "bc" stage of the coal samples before and after microwave heating, and particularly with the raw coal samples. When the coal samples were exposed to microwave radiation, the step size, either in events or hits, was significantly reduced.
These were more uniform in "bc" stage, and the portion of "bc" stage tended to develop linearly. In other words, the crack propagation speeded and the crack size in the coal samples subjected to microwave irradiation became relatively uniform. Because the energy was uniformly released, the rapid failure of the larger fractures rarely occurred. Furthermore, the step changes in the "bc" stage of the cumulative AE hits curve of the CGN1-1 were highly consistent with that in the cumulative AE events curve and were positioned closer to the peak with higher consistency. It indicated that the crack propagation and fracture of the coal samples before microwave heating often produced highenergy events, whereas the coal sample after microwave heating generated mostly low-energy events.

3.3.3. Characteristics of AE Events. Note that the vibration signals from $\mathrm{AE}$ events were received by at least $4 \mathrm{AE}$ sensors in this research. When using such AE events located results to analyze the coal or rock fracture, it was necessary to consider the location error, and the PCI-2 AE acquisition system has its error evaluation index "q"; - "Fall Event Correlations," the closer the value of "q" was to 1 , the more accurate the location results were. Table 4 shows the statistical results of " $q$ " values for AE events on the coal samples during the uniaxial compression test, except for coal sample CGY2-3. The " $\mathrm{q}$ " values for the other coal samples were greater than 0.9 , accounting for more than $75 \%$, whereas the $\mathrm{q}$ values were greater than 0.7 , accounting for more than 90\%. These showed that the AE events locations were accurate and reliable. With the intent of ensuring the accuracy of location results and analysis, the error evaluation index $q$ of the events presented herein was greater than 0.7 . 


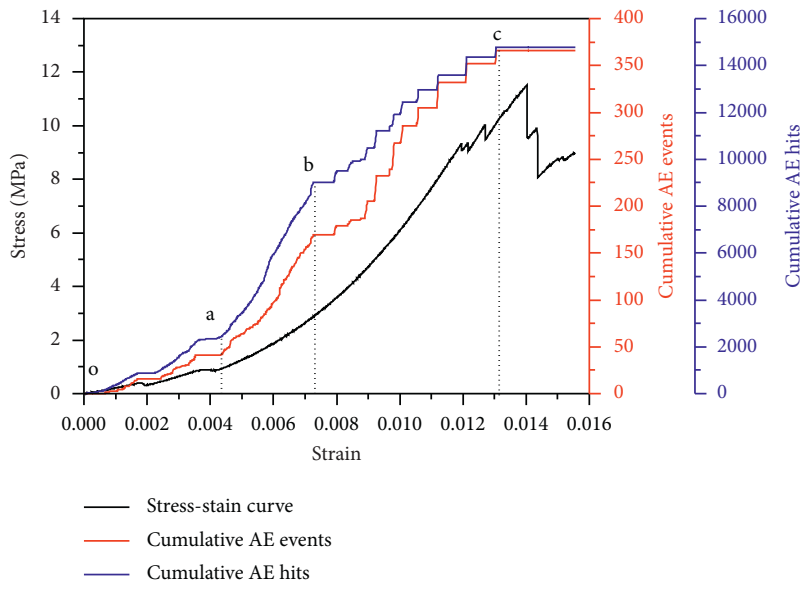

(a)

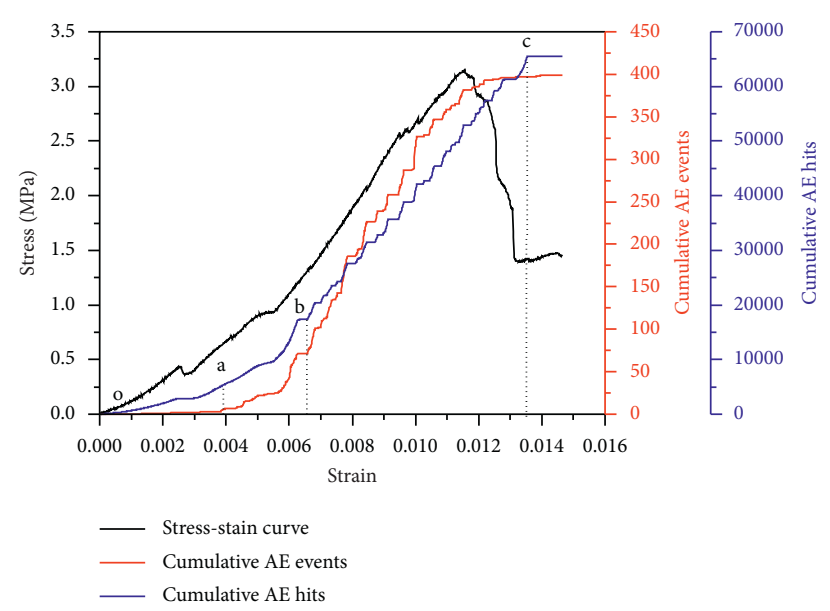

(b)

FIGURE 12: Stress-strain curves and the cumulative AE events and hits for the CGN1-1 and CGY2-2: (a) CGN1-1, (b) CGY2-2.

Table 4: The statistical records of "q" values of AE events for coal samples.

\begin{tabular}{lcccccccccccc}
\hline \multirow{2}{*}{ The q value ranges } & \multicolumn{3}{c}{ CGN (\%) } & \multicolumn{3}{c}{ CGY (\%) } & \multicolumn{3}{c}{ HSN (\%) } & \multicolumn{3}{c}{ HSY (\%) } \\
& $1-1$ & $1-2$ & $1-3$ & $2-1$ & $2-2$ & $2-3$ & $2-1$ & $2-2$ & $2-3$ & $1-1$ & $1-2$ & $1-3$ \\
\hline$>0.7$ & 93.72 & 96.06 & 90.85 & 90.27 & 92.48 & 89.14 & 93.65 & 91.93 & 96.79 & 94.98 & 94.66 & 94.05 \\
$>0.8$ & 88.25 & 92.56 & 85.55 & 87.39 & 87.47 & 82.66 & 90.48 & 85.98 & 93.57 & 89.96 & 87.35 & 86.74 \\
$>0.9$ & 79.51 & 86.43 & 76.24 & 80.75 & 84.71 & 74.72 & 84.44 & 76.91 & 85.71 & 83.54 & 81.62 & 83.52 \\
\hline
\end{tabular}

Figure 13 shows the spatial location and three-plane projection of AE events of the CGN1-1 and CGY2-2. The AE events displayed clustering phenomena in the CGN1-1, whereas the spatial distribution of AE events in the CGY2-2 was relatively uniform. The reason was that the microcracks increased in the coal samples after microwave heating, and the microcracks penetrated each other during the uniaxial compression test for coal samples so that the coal sample was destroyed uniformly and not only along some specific positions. As shown in Figure 13, the number of AE events with energy greater than 1E5aJ (magenta and red spheres) in the CGN1-1 was significantly more than that in the CGY2-2, while there were no AE events with energy less than 10aJ in the CGY2-2, which were consistent with the analyzed results in Section 3.3.1.

3.4. Postpeak Failure Mode. The essence of rock burst failure was the mutual transformation of different forms of energy inside coal samples. When the external loads exceed ultimate strength, the coal sample will release energy in the form of kinetic energy from small coal fragments. Figure 14 presents the uniaxial loading process of the CGN1-1 and HSN2-3 (the coal samples before microwave heating), indicating that the relatively strong burst liability and brittleness characteristics caused small coal pieces to be ejected all around. Particularly, with the raw coal samples before microwave heating (CGN11 ), even larger coal pieces were ejected a few centimeters away and several AE sensors were instantly shaken off, accompanied by a loud sound.
The failure process of coal samples under uniaxial compression can be divided into three stages, including the initiation, propagation, and coalescence of microcracks. The collective behavior of a large number of microcracks was of a special law. Figure 15 shows the real graphs and schematic diagrams of the cracks in the CGN1-1 and CGY2-2. The red solid line represented the cracks in the schematic diagrams. The varied width of stroke indicates the width of the cracks, and the blue dotted line represents the damage zone. The common features of these cracks that appeared in the postpeaking phase of the CGN1-1 and CGY2-2 (before and after microwave heating) were that the cracks broke through along one or more longitudinal cracks. The difference was that there were small transverse cracks between the longitudinal cracks of the CGY2-2. The sound observed from the crack propagation was weak, accompanied by small coal pieces dropping rather than ejection.

It can be seen from Figure 16 that most of the coal samples maintained their relative integral state on the test platform after test. During the movement of the coal samples, the final failure mode of coal samples before microwave heating (CGN) remained unchanged, with the large broken degree (Figure 16(a)). When coal samples after microwave heating (CGY) were removed from the test platform, the coal samples easily collapsed as a whole, displaying even internal failure, with a small broken degree (Figure 16(b)). It is also suggested that a large number of microcracks formed by microwave heating caused the full destruction of the coal sample. After microwave heating during the uniaxial compression test, the coal samples 


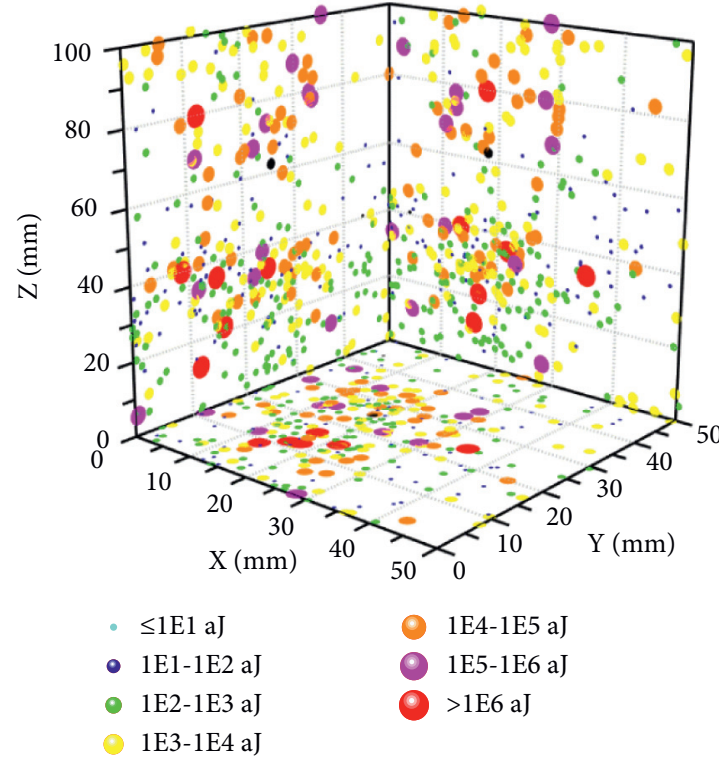

(a)

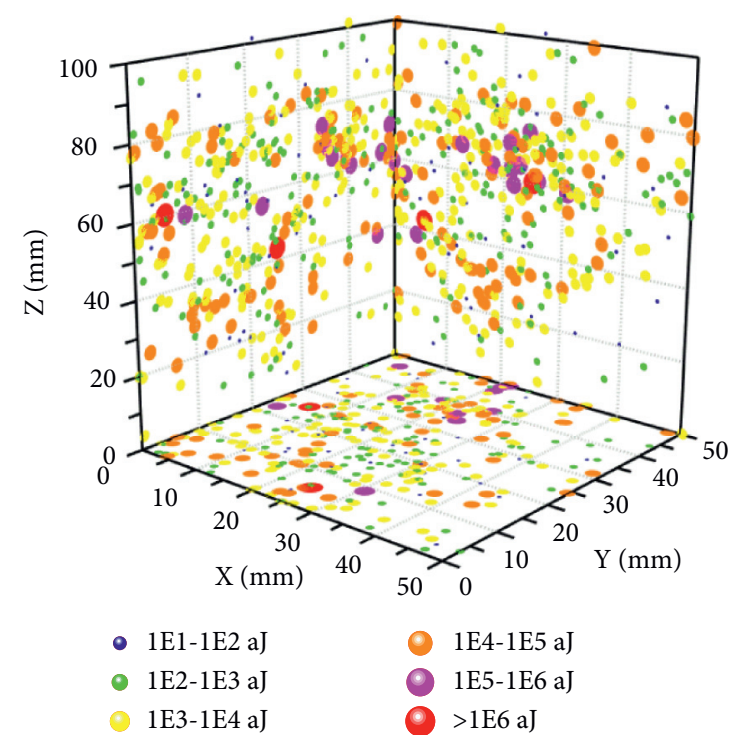

(b)

FIGURE 13: The space location and three-plane projection of AE events of the CGN1-1 and CGY2-2. (a, b) Three-plane projection of AE events of the CGN1-1 and CGY2-2.

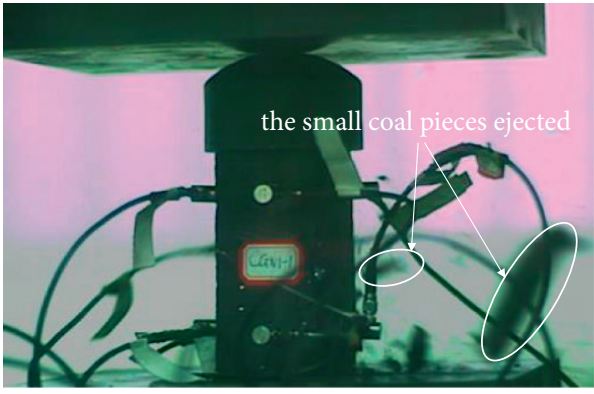

(a)

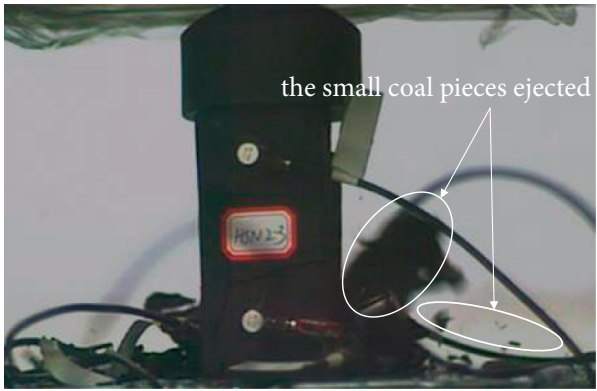

(b)

FIgURE 14: The ejection of small coals in the CGN1-1 and HSN2-3 during uniaxial compression tests: (a) CGN1-1, (b) HSN2-3.

remained intact on the test platform mainly due to the friction between the fragments. But once it was slightly disturbed, the coal sample collapsed as a whole.

\section{Discussion}

4.1. The Weakening Mechanism of Coal Samples with Bursting Liability Subjected to Microwave Irradiation. Mechanism comprehension, prediction, and control are the three major challenges related to rock burst hazards. The prevention and control of rock burst need to reduce the bursting liability of coal effectively. An engineering application method for weakening the bursting liability of coal by microwave irradiation will be carefully introduced in this paper. According to the research results of many scholars in the field of grinding and coal bed methane, microwave irradiation caused the initiation and propagation of microcracks. It has been verified by the results of the reduction in the wave velocity of coal samples after microwave heating. However, it is still not clear how these cracks changed the mechanical properties and the physical phenomena of the coal mass. In this paper, it was shown that the uniaxial compressive strength of raw and water-soaked coal samples decreased by $73.74 \%$ and $46.70 \%$ after microwave irradiation. Furthermore, the bursting energy index decreased by $64.54 \%$ and $32.22 \%$, respectively. From these two parameters, the burst liability of the raw coal sample decreased by one grade. Based on this evidence, we can conclude that when the coal was irradiated by microwave, the increase and expansion of microcracks can reduce the burst liability of coal mass.

The number of new cracks and the size of crack expansion in the coal subjected to microwave irradiation depends on the thermal stress difference between materials with different dielectric constants (inorganic and organic matter). The thermal stress difference depends not only on the sensitivity of the constituents of the coal to the microwave but also depends on the power and time of the microwave. The greater the microwave power, the shorter 


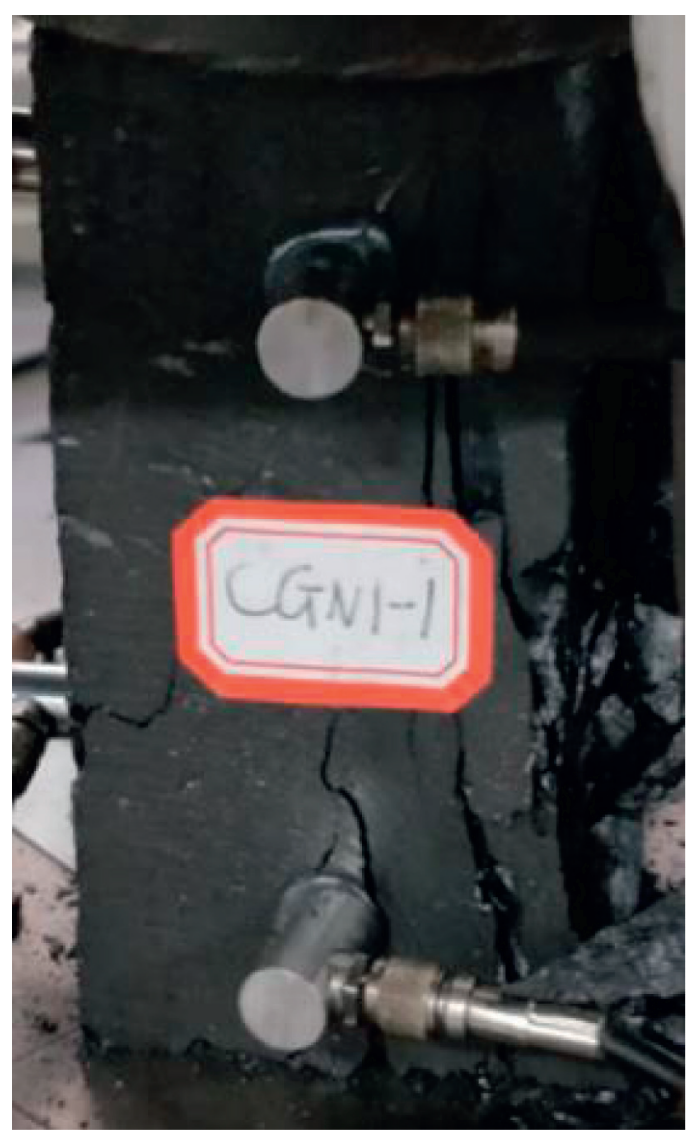

(a)

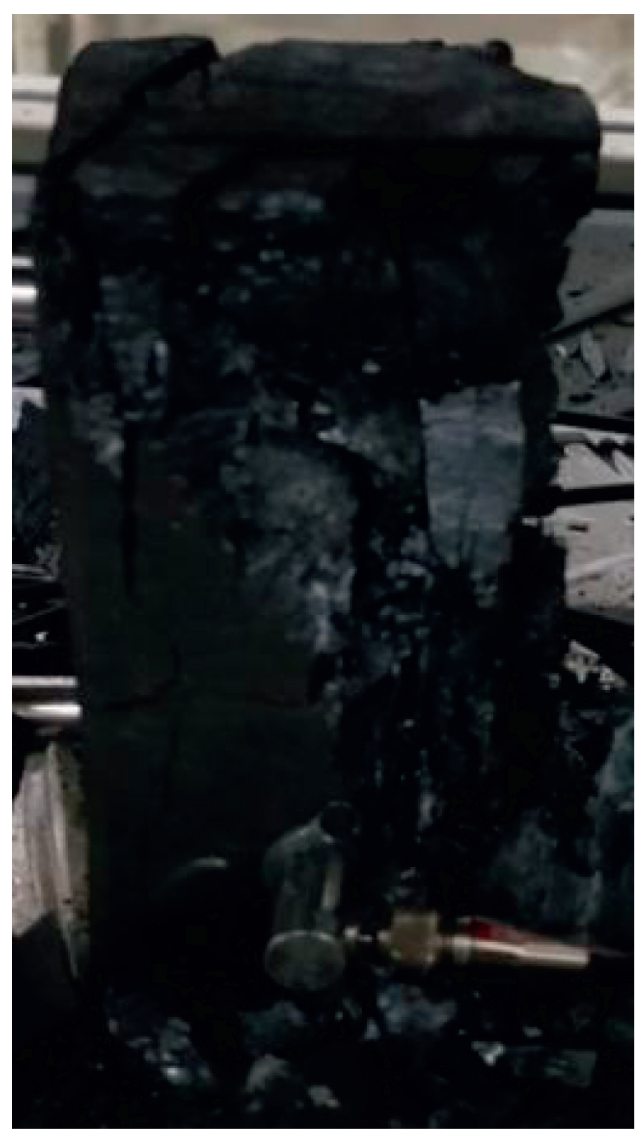

(b)

Figure 15: Continued. 


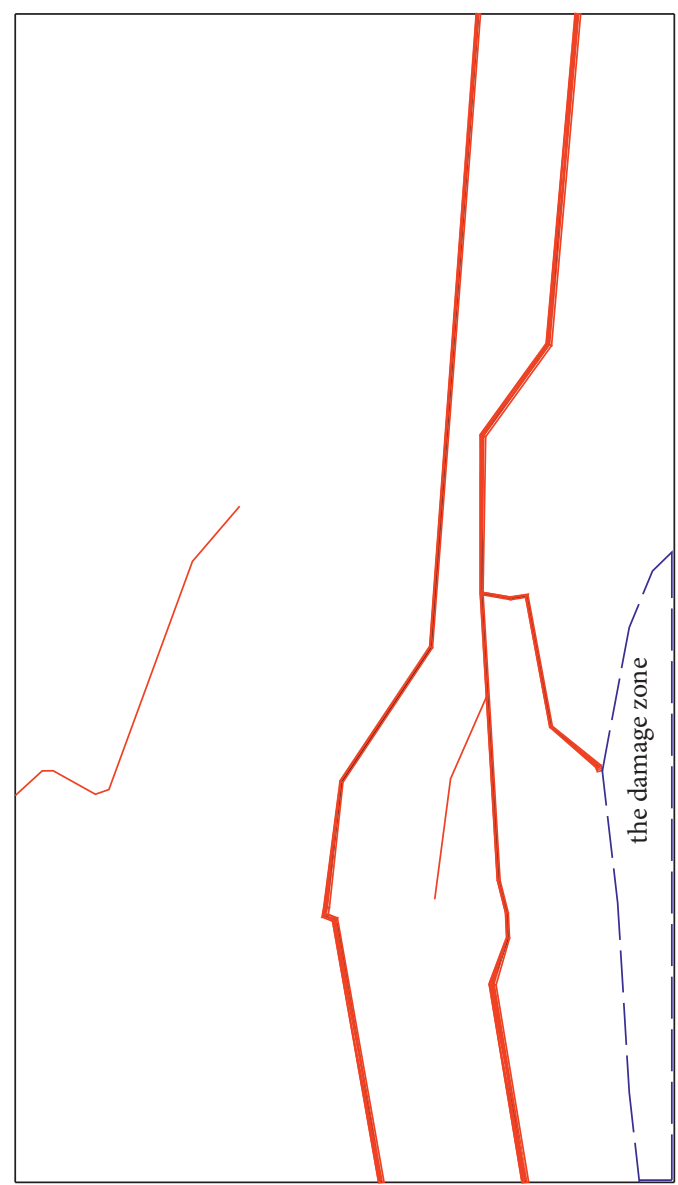

(c)

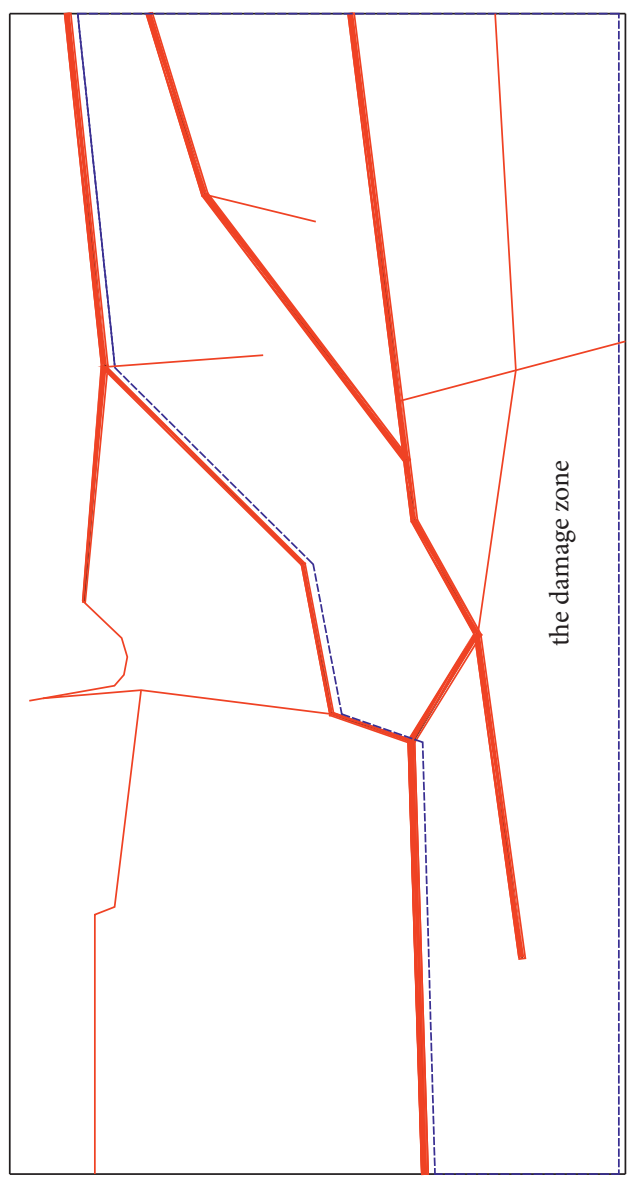

(d)

FIGURE 15: The real graphs and schematic diagrams for the cracks in the CGN1-1 and CGY2-2. (a, c) The real graphs and schematic diagrams for the CGN1-1. (b, d) The real graphs and schematic diagrams for the CGN2-2.

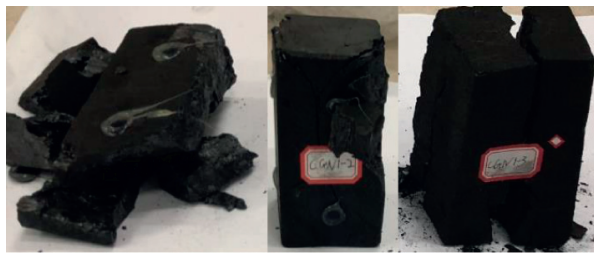

(a)

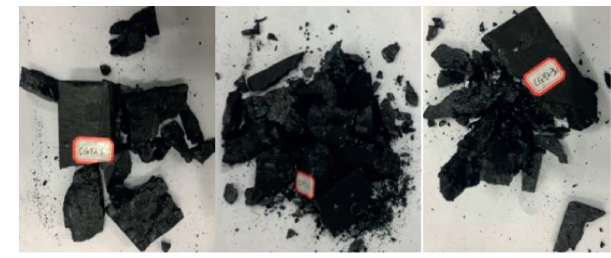

(b)

FIGURE 16: The failure mode of the (a) CGN and (b) CGY.

the time and the greater the thermal stress difference. Meanwhile, the development of microcracks caused by the phase transition of inherent moisture (from liquid to gas) in coal mass cannot be ignored [31]. Although the dielectric property of coal increased with the increase of moisture content, the higher water content strengthened the differential heat [38], The thermal stress difference will not increase infinitely with the increase of moisture content under certain microwave power, and the high moisture content during microwave heating may also affect the phase transition of inherent moisture (over a short time measured in seconds).
As mentioned earlier, when coal samples were heated for $120 \mathrm{~s}$ in the microwave equipment with a power of $1 \mathrm{~kW}$, it decreased the grade of busting liability indexes for watersoaked coal samples (moisture content of $2.68 \%-2.99 \%$ ) was not as good as that of raw coal samples $(1.75 \%-1.80 \%)$. Li et al. [23] studied the permeability changes of coal under microwave irradiation for different water saturation conditions and showed that when the power was $8 \mathrm{~kW}$, and the moisture content reached $6 \%$, the heat conduction was enhanced, but the permeability was reduced. This observation also indicated that a certain microwave power corresponded to a reasonable moisture content range, with the 
event of achieving the optimal weakening effect of coal with bursting liability. In terms of energy release, a single strong energy event will become several medium energy events.

The initiation and expansion of microcracks formed by the microwave irradiation can not only affect the mechanical properties of coal samples but also the characteristics of energy release during the uniaxial compression test. The results showed the proportion of high-energy events and $\mathrm{AE}$ hits with large-scale in the coal samples when subjected to microwave irradiation decreased. Although microwave heating had little effect on the expansion of large-size cracks, it is important in the initiation and propagation of microcracks, which made the integral sample to be destroyed of large-size cracks to multiple cracks with smaller size. In terms of energy release, a high-energy event turned into several low-energy events.

Considering that the discussion on the experimental results was based on the equipment with the microwave power of $1 \mathrm{~kW}$ and heating time of $120 \mathrm{~s}$, further study is still needed to optimize the bursting liability and acoustic emissions of coal samples under other powers and time conditions. In addition, more coal samples with different water contents should be tested as well.

\subsection{The Prospect of Engineering Application for Weakening} Coal Mass by Microwave Irradiation. In the field of microwave-assisted oil recovery and coal bed methane, microwave heat injection-assisted extraction and antireflection have been widely studied [31]. The method needed to use antennas to transmit microwaves down the well or boreholes to irradiate oil reservoirs and coal seams. Based on the concepts presented in previous research, we proposed a method of microwave weakening coal seam with bursting liability for the prevention of rock burst.

There are two main schemes for the engineering application of this method. One is the in-situ modification of coal seams with bursting liability. In this case, the holes can be either drilled from the surface or underground to nonimpactprone coal seams with no bursting liability to the coal seams with bursting liability and then placing the antenna along the borehole into the coal seam for microwave heating. The other scheme is to use the existing drill holes (such as large-diameter pressure relief holes) in the coal seam with bursting liability, which can actively reduce the strength of the coal seam in advance and expand the existing pressure relief range. This method is mainly suitable for relatively hard coal seams $(f \geq 3)$. These two methods could verify the effect of pressure relief by measuring the wave velocity between adjacent holes. Microwave heating is more dangerous in the underground than on the ground, so it is necessary to equip relevant sensors to monitor gas and temperature in the borehole. Meanwhile, the microwave radiation protection net can be arranged on the coal wall of the roadway near the borehole to avoid affecting human health.

\section{Conclusions}

To verify the feasibility of the innovate technique in weakening the bursting liability of the coal seam via the microwave irradiation, comprehensive laboratory tests were conducted with the application of the acoustic emission (AE). Based on the discussion on the experimental tests, the following conclusions can be drawn:

(1) The bursting liability of two types of coal samples was significantly reduced, the evidence of which is the declined UCS and the bursting energy index. Although the bursting liability of raw coal samples was reduced by one grade, the bursting liability of watersoaked coal samples was still in the "weak bursting liability" grade;

(2) The decrease of high-energy events according to statistical analysis of event count and hit count is the other evidence to verify the effectiveness of the microwave irradiation;

(3) The possibility of burst failure of coal samples after microwave heating was greatly reduced from the perspective of energy accumulation and dissipation (reduction of elastic modulus, peak strain, and stress drop in the postpeaking phase).

(4) Subjected to the treatment of the microwave heating, both the crack expansion speed and size of tested coal samples are relatively uniform, which is mutually verified by the uniform events spatial distribution and the fully fractured coal samples.

Note that the main aim of this research is to validate the feasibility of the treatment of coal samples with the bursting liability. Only the single coal seam was investigated. However, further research on the surrounding rock of the coal seams including the roof and floor of which should be conducted before the practice applications.

\section{Data Availability}

The data used to support the findings of this study are included within the article.

\section{Conflicts of Interest}

The authors declare that they have no conflicts of interest.

\section{Acknowledgments}

The research was financially supported by the National Natural Science Foundation of China (no. 51764050) and the Fundamental Research Funds for the Central Universities (no. 2017CXNL01).

\section{References}

[1] L. Tan, T. Ren, L. Dou, X. Yang, M. Qiao, and H. Peng, "Analytical stress solution and mechanical properties for rock mass containing a hole with complex shape," Theoretical and Applied Fracture Mechanics, vol. 114, Article ID 103002, 2021.

[2] X. Liu, S. Song, Y. Tan et al., "Similar simulation study on the deformation and failure of surrounding rock of a large section chamber group under dynamic loading," International Journal of Mining Science and Technology, vol. 31, no. 3, pp. 495-505, 2021. 
[3] W. Cai, L. Dou, M. Zhang, W. Cao, J.-Q. Shi, and L. Feng, “A fuzzy comprehensive evaluation methodology for rock burst forecasting using microseismic monitoring," Tunnelling and Underground Space Technology, vol. 80, pp. 232-245, 2018.

[4] National Coal Mine Safety Administration, Detailed Rules for Prevetion and Control of Rock Burst in Coal Mines, Translated by China Coal Industry, pp. 5-6, Publishing House, Beijing, China, 2018.

[5] A. Cao, G. Jing, Y.-l. Ding, and S. Liu, "Mining-induced static and dynamic loading rate effect on rock damage and acoustic emission characteristic under uniaxial compression," Safety Science, vol. 116, pp. 86-96, 2019.

[6] H. Zhao, T. Ren, and A. Remennikov, "A hybrid tubular standing support for underground mines: compressive behaviour," International Journal of Mining Science and Technology, vol. 31, no. 2, pp. 215-224, 2021.

[7] X. Chen, L. Li, L. Wang, and L. Qi, “The current situation and prevention and control countermeasures for typical dynamic disasters in kilometer-deep mines in China," Safety Science, vol. 115, pp. 229-236, 2019.

[8] S. R. Ford, D. S. Dreger, and W. R. Walter, "Source characterization of the 6 August 2007 crandall canyon mine seismic event in central Utah," Seismological Research Letters, vol. 79, no. 5, pp. 637-644, 2008.

[9] B. Hebblewhite and J. Galvin, "A review of the geomechanics aspects of a double fatality coal burst at austar colliery in NSW, Australia in april 2014," International Journal of Mining Science and Technology, vol. 27, no. 1, pp. 3-7, 2017.

[10] C. Zhang, I. Canbulat, B. Hebblewhite, and C. R. Ward, "Assessing coal burst phenomena in mining and insights into directions for future research," International Journal of Coal Geology, vol. 179, pp. 28-44, 2017.

[11] M. Bukowska, "The rockbursts in the upper silesian coal basin in Poland," Journal of Mining Science, vol. 48, no. 3, pp. 445-456, 2012.

[12] G. Mutke, J. Dubiński, and A. Lurka, "New criteria to assess seismic and rock burst hazard in coal mines/nowe kryteria dla oceny zagrożenia sejsmicznego I tạpaniami W kopalniach węgla kamiennego," Archives of Mining Sciences, vol. 60, no. 3 , pp. 743-760, 2015.

[13] C. Wang, S. Gong, C. Zhang, A. Cao, and I. Canbulat, "A statistical method to assess the data integrity and reliability of seismic monitoring systems in underground mines," Rock Mechanics and Rock Engineering, pp. 1-17, 2021.

[14] Q. Qi, Y. Li, S. Zhao, N. Zhang, W. Zheng, and H. Li, "Seventy years development of coal mine rockburst in China: establishment and consideration of theory and technology system," Coal Science and Technology, vol. 47, no. 9, pp. 1-40, 2019.

[15] G.-F. Wang, G. Li, L.-M. Dou, Z.-L. Mu, S.-Y. Gong, and W. Cai, "Applicability of energy-absorbing support system for rockburst prevention in underground roadways," International Journal of Rock Mechanics and Mining Sciences, vol. 132, no. 6, Article ID 104396, 2020.

[16] S.-C. Wang, L.-M. Dou, Z.-Y. Wang, J.-Z. Bai, Y.-J. Chai, and P. Li, "Mechanism of coal bursts induced by horizontal section mining of steeply inclined coal seams and application of microseismic multiparameter monitoring in early warning," Advances in Civil Engineering, vol. 2020, no. 15, pp. 1-14, Article ID 1048624, 2020.

[17] N. Zhou, H. Liu, J. Zhang, and H. Yan, "Study on rock burst event disaster and prevention mechanisms of hard roof," Advances in Civil Engineering, vol. 2019, no. 1, 14 pages, Article ID 6910139, 2019.
[18] S. Zhang, Y. Li, B. Shen, X. Sun, and L. Gao, "Effective evaluation of pressure relief drilling for reducing rock bursts and its application in underground coal mines," International Journal of Rock Mechanics and Mining Sciences, vol. 114, pp. 7-16, 2019.

[19] Z. Liu, A. Cao, X. Guo, and J. Li, "Deep-hole water injection technology of strong impact tendency coal seam-a case study in Tangkou coal mine," Arabian Journal of Geosciences, vol. 11, no. 2, pp. 12-20, 2018.

[20] M. Hossain Arafat, K. Chinna, P. Ganesan, and J. Jewaratnam, "Optimization of process parameters for microwave pyrolysis of oil palm fiber (OPF) for hydrogen and biochar production," Energy Conversion and Management, vol. 133, pp. 349-362, 2017.

[21] M. Al-Harahsheh and S. W. Kingman, "Microwave-assisted leaching-a review,” Hydrometallurgy, vol. 73, no. 3, pp. 189-203, 2004.

[22] S. Marland, B. Han, A. Merchant, and N. Rowson, "The effect of microwave radiation on coal grindability," Fuel, vol. 79, no. 11, pp. 1283-1288, 2000.

[23] H. Li, B. Lin, Z. Chen, Y. Hong, and C. Zheng, "Evolution of coal petrophysical properties under microwave irradiation stimulation for different water saturation conditions," Energy \& Fuels, vol. 31, no. 9, pp. 8852-8864, 2017.

[24] B. K. Sahoo, S. De, and B. C. Meikap, "Improvement of grinding characteristics of Indian coal by microwave pretreatment," Fuel Processing Technology, vol. 92, no. 10, pp. 1920-1928, 2011.

[25] H. Li, B. Lin, W. Yang et al., "Experimental study on the petrophysical variation of different rank coals with microwave treatment," International Journal of Coal Geology, vol. 154155, pp. 82-91, 2016.

[26] M. S. Seehra, A. Kalra, and A. Manivannan, "Dewatering of fine coal slurries by selective heating with microwaves," Fuel, vol. 86, no. 5-6, pp. 829-834, 2007.

[27] T. Uslu and Ü. Atalay, "Microwave heating of coal for enhanced magnetic removal of pyrite," Fuel Processing Technology, vol. 85, no. 1, pp. 21-29, 2004.

[28] S. Singh, V. B. Neculaes, V. Lissianski et al., "Microwave assisted coal conversion," Fuel, vol. 140, pp. 495-501, 2015.

[29] E. Lester, S. Kingman, and C. Dodds, "Increased coal grindability as a result of microwave pretreatment at economic energy inputs," Fuel, vol. 84, no. 4, pp. 423-427, 2005.

[30] G. Hu, N. Yang, G. Xu, and J. Xu, "Experimental investigation on variation of physical properties of coal samples subjected to microwave irradiation," Journal of Applied Geophysics, vol. 150, pp. 118-125, 2018.

[31] H. Li, S. Shi, J. Lu, Q. Ye, Y. Lu, and X. Zhu, "Pore structure and multifractal analysis of coal subjected to microwave heating," Powder Technology, vol. 346, pp. 97-108, 2019.

[32] E. Lester and S. Kingman, "Effect of microwave heating on the physical and petrographic characteristics of a U.K. coal," Energy \& Fuels, vol. 18, no. 1, pp. 140-147, 2004.

[33] B. Gao, H. Li, L. Li, and C. Su, "Acoustic emission and fractal characteristics of saturated coal samples in the failure process," Journal of Mining \& Safety Engineering, vol. 32, no. 4, pp. 665-670+676, 2015 .

[34] E. Eberhardt, D. Stead, B. Stimpson, and R. S. Read, "Identifying crack initiation and propagation thresholds in brittle rock," Canadian Geotechnical Journal, vol. 35, no. 2, pp. 222-233, 1998.

[35] H. Li, H. Li, B. Gao, D. Jiang, and J. Feng, "Study of acoustic emission and mechanical characteristics of coal samples 
under different loading rates," Shock and Vibration, vol. 2015, Article ID 458519, 11 pages, 2015.

[36] C. H. Scholz, "On the stress dependence of the earthquake b value," Geophysical Research Letters, vol. 42, no. 5, pp. 1399-1402, 2015.

[37] F. Meng, H. Zhou, Z. Wang et al., "Experimental study on the prediction of rockburst hazards induced by dynamic structural plane shearing in deeply buried hard rock tunnels," International Journal of Rock Mechanics and Mining Sciences, vol. 86, pp. 210-223, 2016.

[38] W. Fan, C. Jia, W. Hu et al., "Dielectric properties of coals in the low-terahertz frequency region," Fuel, vol. 162, pp. 294304, 2015. 